\title{
What is the benefit of associating a blockade ilioinguinal and local anesthetic infiltration in elderly patients undergoing hernia repair surgery: a double-blind randomized study
}

\author{
Luana Vessicchio, Maria Luisa Mingione, Giuseppe Dimarzio, A d'Elia, Giuseppe Izzo, Francesca Grassia, \\ Biagio Lettieri*
}

From 26th National Congress of the Italian Society of Geriatric Surgery

Naples, Italy. 24-26 October 2013

\section{Introduction}

Among the different anesthetic techniques used to attend hernioplasty current evidence supports the use of local anesthesia by infiltration because it determines a shorter post-operative recovery, fewer complications and lower overall costs 1 ,. However, despite these advantages the local anesthesia by infiltration is rarely used 2 . In order to improve intraoperative analgesia ilioinguinal block combined with an infiltration of local anesthetic can represent the rational, but there are no data from randomized trials to support this approach in elderly patients. The aim of our study conducted in doubleblind, randomized, and is to verify if the additional ilioinguinal blockade could improve the intra-operative analgesia in the intervention of inguinal hernia repair performed under local anesthesia by infiltration.

\section{Materials and methods}

64 patients who underwent elective surgery for inguinal hernia repair with gradual infiltration of local anesthetic were randomized in 2 groups, in double-blind. In the first group the patients were subjected to an additional ilioinguinal block with $10 \mathrm{ml}$ of bupivacaine $0.25 \%$, and others patients were subjected with isotonic saline to placebo effect. All operations of hernia repair were performed by an experienced team of surgeons. The criteria for inclusion in the study were: first intervention of inguinal hernia repair, age over 70 years, ASA class and

\footnotetext{
* Correspondence: biagio.lettieri@unina2.it
Dept. of Anesth. Surgical and Emergency Sciences-Intensive Care Unit - ॥

* Correspondence: biagio.lettieri@unina2.it
Dept. of Anesth. Surgical and Emergency Sciences-Intensive Care Unit - ॥ University of Naples, Italy
}

(C) 2013 Vessicchio et al; licensee BioMed Central Ltd. This is an Open Access article distributed under the terms of the Creative Commons Attribution License (http://creativecommons.org/licenses/by/2.0), which permits unrestricted use, distribution, and reproduction in any medium, provided the original work is properly cited.

\section{Results}

Between the two groups there were no differences in age, use of sedation and amount of bupivacaine infiltration anesthesia. The intra-operative dose of midazolam for sedation was low $(1.0 \mathrm{mg})$ and similar in both groups.

The median VAS score intra-operative was 9 in the group treated with additional ilioinguinal block while it was 13 in the group treated with placebo ilioinguinal block $(P=0.02)$ (Figure 1). There was no difference in pain scores or analgesic requirements at 24 and 48 hours after surgery (Figure 1). The distribution of intraoperative VAS scores showed a greater number $(\mathrm{P}<0.05)$ of patients with VAS score $\geq 30$ intra-operative in the placebo group compared to patients treated with ilioinguinal block (Figure 2). 

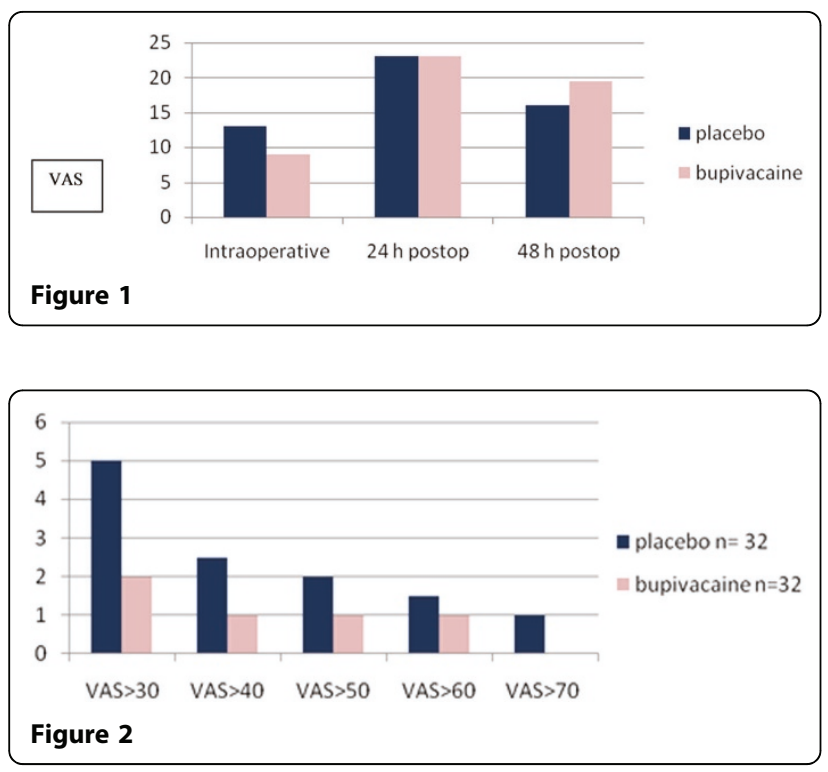

The results of this study have shown that the further randomized ilioinguinal block preoperative together with a gradual procedure for local infiltration anesthesia improves the intra-operative analgesia during repair of the inguinal hernia using prosthesis. These findings may have important clinical implications as it is well known that the infiltration of local anesthetic may be the most convenient technique for the repair of the inguinal hernia 3 .. However, this technique is not widely used, probably because of the risk of intra-operative pain, and causes of surgical preferences, and the traditional use of monitored anesthesia with propofol and opioids for short-term action 4 . The results of this study demonstrate that a block ilioinguinal can provide better postoperative pain relief after inguinal hernia repair in elderly patients compared to placebo. The improved intra-operative pain associated with ilioinguinal block does not have, however, effect on the subsequent (24-48 hours) pain scores or analgesic use. In conclusion, the additional use of a preoperative ilioinguinal block the procedure of local infiltration anesthesia for inguinal hernia repair improves the intra-operative pain relief and is therefore recommended. This technique can support more widespread use of local anesthesia for inguinal hernia repair.

Published: 16 September 2013

\section{References}

1. Akyol C, Kocaay F, Orozakunov E, Genc V, Kepenekci Bayram I, Cakmak A, Baskan S, Kuterdem E: Outcome of the patients with chronic mesh infection following open inguinal hernia repair. J Korean Surg Soc 2013, 84(5):287-91, doi:10.4174/jkss.2013.84.5.287. Epub 2013 Apr 24.

2. Neumayer $L$, Giobbie-Hurder A, Jonasson $O$, et al: Open mesh versus laparoscopic mesh repair of inguinal hernia. N Engl J Med 2004, 350:1819-27.
3. Nordin P, Zetterström H, Gunnarsson U, Nilsson E: Local, regional or general anaesthesia in groin hernia repair: multi-center randomized trial. Lancet 2003, 362:853-8.

4. Kulacoglu H, Ergul Z, Esmer AF, Sen T, Akkaya T, Elhan A: Percutaneous ilioinguinal-iliohypogastric nerve block or step-by-step local infiltration anesthesia for inguinal hernia repair: what cadaveric dissection says? J Korean Surg Soc 2011, 81(6):408-13, doi: 10.4174/jkss.2011.81.6.408. Epub 2011 Nov 25.

doi:10.1186/1471-2482-13-S1-A48

Cite this article as: Vessicchio et al:: What is the benefit of associating a blockade ilioinguinal and local anesthetic infiltration in elderly patients undergoing hernia repair surgery: a double-blind randomized study. BMC Surgery 2013 13(Suppl 1):A48.

\section{Submit your next manuscript to BioMed Central} and take full advantage of:

- Convenient online submission

- Thorough peer review

- No space constraints or color figure charges

- Immediate publication on acceptance

- Inclusion in PubMed, CAS, Scopus and Google Scholar

- Research which is freely available for redistribution

Submit your manuscript at www.biomedcentral.com/submit
C BioMed Central 